Research Paper:

\title{
Effect of Chlorhexidine and Orthodentol Mouthwash on crosshark Oral Hygiene of Patients Who Underwent Mechanical Ventilation, Hospitalized in Intensive Care Unit
}

\author{
Hojjat Mirzakhani ${ }^{1}$, Haydeh Heidari ${ }^{1 *}$, Ali Hasanpour ${ }^{1}$, Fatemeh Deris
}

1. Department of Nursing, School of Nursing and Midwifery, Shahrekord University of Medical Sciences, Shahr-e Kord, Iran.

2. Department of Epidemiology and Biostatistics, School of Public Health, Shahrekord University of Medical Sciences, Shahr-e Kord, Iran.

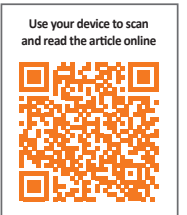

Citation: Mirzakhani, H. et al., 2017. Effect of Chlorhexidine and Orthodentol Mouthwash on Oral Hygiene of Patients Who Underwent Mechanical Ventilation, Hospitalized in Intensive Care Unit. Journal of Client-Centered Nursing Care, 3(2), pp. 161-166. https://doi.org/10.32598/jecnc.3.2.161

https://doi.org/10.32598/jcenc.3.2.161

Article info:

Received: 08 Nov. 2016

Accepted: 16 Mar. 2017

Keywords:

Special care,

Chlorhexidine rinse,

Orthodentol, Oral

hygiene, Intubated patients
A B S T R A C T

Background: Providing oral hygiene in patients with a tracheal tube in the mouth is one of the most important tasks of nurses. This study has been conducted with the aim of comparing the effects of two mouthwash solutions (chlorhexidine and orthodentol) on the oral hygiene of patients with respiratory ventilation device and hospitalized in intensive care units.

Methods: This is a clinical trial in which 90 patients with oral tracheal tube entered the study through simple sampling method. Inclusion criteria were being insensitive to herbal compounds and aged 15-85 years. They were divided randomly into two intervention (orthodentol) and control (chlorhexidine) groups. Each group had 45 subjects. The Beck Oral Hygiene Checklist was used to collect data (before and after intervention). Data were analyzed using SPSS software.

Results: Patients in intervention and control groups were similar in terms of demographic characteristics, oral hygiene, and other characteristics. Oral hygiene in patients in both orthodentol and chlorhexidine groups had a significant improvement after intervention.

Conclusion: The comparison of orthodentol and chlorhexidine oral mucosal effects showed that oral hygiene of patients hospitalized in intensive care units was improved to a certain extent. Considering the benefits of herbal compounds, orthodentol mouthwash can be mentioned as an appropriate alternative for chlorhexidine.

\section{Background}

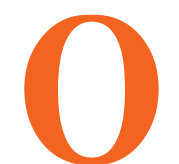

ne of the basic cares provided by nurses in Intensive Care Units (ICU) is maintaining oral hygiene of the patients (Miranda et al. 2015; Safar Abadi \&
Ghaznavirad 2012). These patients are often fitted with a tracheal tube in mouth and undergo mechanical ventilation. Caring programs for patients in ICU aim to make the patients feel relieved and comforted (Safar Abadi \& Ghaznavirad 2012). In general, patients may have poor oral hygiene, but patients with mechanical ventilation

\section{* Corresponding Author:}

Haydeh Heidari, PhD

Address: Department of Nursing, School of Nursing and Midwifery, Shahrekord University of Medical Sciences, Shahr-e Kord, Iran.

Tel: $+98(38) 33336699$

E-mail: haydehheidari@gmail.com 
system and hospitalized in special units are more prone to risk and vulnerability than the rest of the patients because the tracheal tube in these patients increases the accumulation of bacteria in the oral mucosa. Taking multiple medications increases the risk of dry mouth, which affects the oral hygiene (Percival \& Williams 2014). Many factors cause problems in the mouth and teeth in patients with severe disease, anesthetized patients, and patients undergoing mechanical ventilation. Long open mouth and the resulting dryness, and the use of immunosuppressive drugs and antibiotics cause inflammation of the mouth and gums, tooth decay, dental plaques, as well as infection of the tissues around the teeth (Panchabhai et al. 2009). Some studies have shown that nurses perform oral cares based on common practices and that there is no particular way to perform oral examination. Many nurses believe that oral care disturbs the patient, and thus, they have given less importance to oral care. Various reasons, such as lack of oral care, lack of awareness, and lack of scientific standards, different methods and regimes for oral care are effective in this regard (Grap \& Munro 2003; Berry 2011).

Studies have shown that oral hygiene of patients in intensive units is more neglected than in any other place. A study has showed that a significant number of patients hospitalized in the ICU had poor oral hygiene status at the time of admission. Instructions published by the Center for Disease Prevention and Control on the prevention of pneumonia in hospital highlighted the preparation and implementation of a comprehensive oral care program, which included the use of an antibacterial agent in areas where patients are prone to hospitalacquired pneumonia (Browne et al. 2011; Scannapieco, Wang \& Shiau 2001). Health and oral care should be considered as one of the most important parts of nursing care. There are two main ways to maintain oral hygiene and remove tooth plaque and germs: mechanical method (toothbrush) and the drug method (including antibiotics and mouthwashes) (Fourrier et al. 2000). However, certain solutions and devices such as oxygenated water and sodium bicarbonate used by nurses to care for the mouth are not desirable (Aronovitch 1997).

Chlorhexidine is a broad-spectrum antibacterial agent that affects the gram-positive and germ-negative organisms (Berry et al. 2007). This solution is highly effective in reducing microbial contamination and establishing oral hygiene. Recently, the Ortodontal Oral Mouthwash, which contains extracts of Khouzestani Savory (carvacrol), was proposed as a mouthwash (Seghatoleslami et al 2004). Khouzestani Savory is an indigenous plant of Iran, widely distributed in the northern and western parts and south of Iran. Its extract has 30\% carvacrol, which is a safe and non-toxic ingredient having many antimicrobial effects. 10\% solution of carvacrol obtained from Khouzestani Savory has considerable palpable effects on toothache (Farsam etal 2004; Pappen et al. 2010). Studies have shown that the Ortodontal herbal mouthwash is a natural formulation that removes almost all infectious problems and inflammation of the mouth and gums (Hashemi et al. 2012; Shafizadeh 2002). This cheap and widely available mouthwash has a high disinfection strength and causes pharyngeal disinfection; it is also safe when swallowed (Fathi et al. 2011). Given this background, the present study aimed to compare the effects of orthodentoland chlorhexidine on oral hygiene of hospitalized patients with an endotracheal tube in special units. 1. Patients with an endotracheal tube underwent mechanical ventilation in Intensive Care Unit need to care and wash their mouth to prevent pneumonia caused by mechanical ventilation 2 . Now, the chlorhexidine mouthwash is used routinely (Munro et al. 2009) and, 3 . The benefits of herbal compounds, and their fewer side effects than the chemical compounds.

\section{Materials \& Methods}

For this study, the sample size was calculated based on a similar study (Adib Hajbaghery, Ansari \& Azizi Fini 2011). A total of 90 anesthetized patients hospitalized in ICUs of Vali Asr (PBUH) Educational and Therapeutic Center of Boroujen and Kashani Educational and Therapeutic Center of Shahrekord were selected using simple convenient sampling. Those patients who satisfied the inclusion and exclusion criteria were then divided into intervention (45 People) and control (45 People) groups. The inclusion criteria included patients should have an endotracheal tube through the mouth, age should be 15-85 years, less than 8 hours should have passed post hospitalization and patient intubation in the ICU, should have no susceptibility to herbal compounds, absence of any specific damage by intubation or airway, and no specific lesion in the mouth. Exclusion criteria included transferring a patient from ICU or his/her death before completion of the study, creating any specific damage by intubation or airway or any other physical factor, and the reluctance of the legal guardian to continue participation in the study.

Caring and mouthwash in the intervention group were done using 10\% Ortodontal Herbal mouthwash, and in the control group, it was done using $12.2 \%$ Chlorhexidine mouthwash. The number, time, and manner of mouthwash were identical in both groups. At the beginning of the study, informed consent was taken from the patient's legal guardian. Information about the patient's 
basic characteristics such as history of illness, cause of hospitalization, medicines used (antibiotics), and the results of the initial assessment of oral hygiene condition were recorded in the demographic information list. Oral hygiene assessment was measured using the Beck Oral Assessment Scale (BOAS) and Oral Mucosal Plaque Score (MPS) (Safar Abadi \& Ghaznavirad 2012).Validity of instruments used was evaluated by 10 faculty members of the university, and the necessary amendments were made. The researcher evaluated instrument reliability for 10 patients in ICUs. Regarding the normal distribution of checklist scores, Cronbach's alpha coefficient was used to determine the reliability; its Cronbach's alpha coefficient equaled to $\alpha=0.862$. Oral hygiene Assessment Checklist has 5 scales (lips, mucus and gums, teeth, tongue, and saliva); each of which was divided into 4 parts and scored 1 to 4 . The overall score of this instrument is 5-20. Lower score indicates oral hygiene (no problem and disorder), and the higher score shows the symptom of more severe disorder. Therefore, score 5 means no disruption, score of 6-10 means a mild impairment, score of 11-15 means average disorder, and score 16-20 means severe disorder.

\section{Results}

Most of the patients in the control group (chlorhexidine) were male (53.3\%) and had an average age of 54.67 years. In the intervention group (orthodentol), male constituted 55.6 percent, and they had an average age of 57.80 years. In the control group, the most common causes of hospitalization were laparotomy and multiple traumas with $26.7 \%$ and $22.2 \%$ patients, respectively. In the intervention group, the most common causes of hospitalization were multiple traumas, Intracranial Hemorrhage (ICH), and Cerebrovascular Accident (CVA) with $22.2 \%$ and $15.6 \%$, respectively (Table 1 ).

The comparison of oral hygiene in both the groups showed that there was no significant difference between them before intervention and at the time of the investigation (first 8 hours) using the duplicate values test. In

Table 1. Comparing descriptive indices in study group with separated study variables

\begin{tabular}{|c|c|c|c|c|}
\hline & & $\begin{array}{c}\text { Chlorhexidine }(n=45) \\
\text { Frequency }(\%)\end{array}$ & $\begin{array}{c}\text { Orthodentol }(n=45) \\
\text { Frequency }(\%)\end{array}$ & $\mathbf{P}$ \\
\hline \multirow{2}{*}{ Sex } & Female & $21(46.7)$ & $20(44.4)$ & \multirow{2}{*}{0.832} \\
\hline & Male & $24(53.3)$ & $25(55.6)$ & \\
\hline \multirow{2}{*}{ Antibiotics } & No & $2(4.4)$ & $5(11.1)$ & \multirow{2}{*}{0.434} \\
\hline & Yes & 43 (95.6) & 40 (88.9) & \\
\hline \multirow{2}{*}{ Ceftazidine } & No & $32(71.1)$ & $37(82.2)$ & \multirow{2}{*}{0.071} \\
\hline & Yes & $13(28.9)$ & $8(17.8)$ & \\
\hline \multirow{2}{*}{ Vancomycin } & No & 31 (68.9) & $37(82.2)$ & \multirow{2}{*}{0.141} \\
\hline & Yes & $14(31.1)$ & $8(17.8)$ & \\
\hline \multirow{2}{*}{ Meropenem } & No & $37(82.2)$ & $38(84.4)$ & \multirow{2}{*}{0.777} \\
\hline & Yes & $8(17.8)$ & $7(15.6)$ & \\
\hline \multirow{2}{*}{ Ciprofloxacin } & No & $396(86.7)$ & 40 (88.9) & \multirow{2}{*}{0.748} \\
\hline & Yes & $6(13.3)$ & $5(11.1)$ & \\
\hline \multirow{2}{*}{ Ceftriaxone (rosphim) } & No & 31 (68.9) & $24(53.3)$ & \multirow{2}{*}{0.130} \\
\hline & Yes & $14(31.1)$ & $21(46.7)$ & \\
\hline \multirow{2}{*}{ Metronidazole } & No & $38(84.4)$ & $42(93.3)$ & \multirow{2}{*}{0.180} \\
\hline & Yes & $7(15.6)$ & $3(6.7)$ & \\
\hline \multirow{2}{*}{ Clindamycin } & No & $41(91.1)$ & $42(93.3)$ & \multirow{2}{*}{1.000} \\
\hline & Yes & $4(8.9)$ & $3(6.7)$ & \\
\hline \multirow{2}{*}{ Gentamicin } & No & 44 (97.8) & 40 (88.9) & \multirow{2}{*}{0.203} \\
\hline & Yes & $1(2.2)$ & $5(11.1)$ & \\
\hline \multirow{2}{*}{ Kephelin (Cefazolin) } & No & 40 (88.9) & 41 (91.1) & \multirow{2}{*}{1.000} \\
\hline & Yes & 5 (11.1) & 4 (8.9) & \\
\hline \multirow{2}{*}{ Amikacin } & No & 43 (95.6) & 45 (100) & \multirow{2}{*}{0.494} \\
\hline & Yes & $2(4.4)$ & $0(0)$ & \\
\hline \multirow{2}{*}{ Acyclovir } & No & $44(97.8)$ & $45(100)$ & \multirow{2}{*}{1} \\
\hline & Yes & $1(2.2)$ & $0(0)$ & \\
\hline
\end{tabular}


Table 2. Test results of duplicate values for oral hygiene variables at the time of examination according to the study groups

\begin{tabular}{|c|c|c|c|c|}
\hline Variable & Time & $\begin{array}{l}\text { Chlorhexidine } \\
\text { Mean (SD) }\end{array}$ & $\begin{array}{l}\text { Orthodentol } \\
\text { Mean (SD) }\end{array}$ & Total in Time \\
\hline Lips & $\begin{array}{c}8 \\
48 \\
72\end{array}$ & $\begin{array}{c}2.16(64) \\
2.29(0.65) \\
2.42(0.58)\end{array}$ & $\begin{array}{l}1.91(0.56) \\
2.33(0.60) \\
2.24(0.57)\end{array}$ & $\begin{array}{l}2.03(0.61) \\
2.31(0.57) \\
2.33(0.58)\end{array}$ \\
\hline Total & & $2.2(0.06)$ & $2.16(0.06)$ & \\
\hline Gums and oral mucosa & $\begin{array}{c}8 \\
48 \\
72\end{array}$ & $\begin{array}{l}2.20(0.97) \\
2.60(0.78) \\
2.62(0.81)\end{array}$ & $\begin{array}{l}2.07(0.96) \\
2.40(0.89) \\
2.69(0.79)\end{array}$ & $\begin{array}{l}2.13(0.96) \\
2.50(0.84) \\
2.66(0.80)\end{array}$ \\
\hline Total & & $2.47(0.10)$ & $2.39(0.10)$ & \\
\hline Tongue & $\begin{array}{c}8 \\
48 \\
72\end{array}$ & $\begin{array}{l}2.20(0.63) \\
2.29(0.66) \\
2.42(0.75)\end{array}$ & $\begin{array}{l}2.04(0.74) \\
2.510 .87) \\
2.490 .82)\end{array}$ & $\begin{array}{l}2.12(0.68) \\
2.40(0.78) \\
2.46(0.78)\end{array}$ \\
\hline Total & & $2.35(0.75)$ & $2.35(0.09)$ & \\
\hline Tooth & $\begin{array}{c}8 \\
48 \\
72\end{array}$ & $\begin{array}{l}2.04(0.74) \\
2.00(0.56) \\
2.13(0.46)\end{array}$ & $\begin{array}{l}1.89(0.57) \\
2.02(0.62) \\
2.04(0.56)\end{array}$ & $\begin{array}{l}0.97(0.66) \\
2.01(0.59) \\
2.09(0.51)\end{array}$ \\
\hline Total & & $2.06(0.07)$ & $1.99(0.07)$ & \\
\hline Saliva & $\begin{array}{c}8 \\
48 \\
72\end{array}$ & $\begin{array}{l}2.73(0.50) \\
2.71(0.51) \\
2.80(0.55)\end{array}$ & $\begin{array}{l}2.76(0.53) \\
2.67(0.64) \\
2.84(0.56)\end{array}$ & $\begin{array}{l}2.74(0.51) \\
2.69(0 . .57) \\
2.82(0.55)\end{array}$ \\
\hline Total & & $2.75(0.06)$ & $2.76(0.06)$ & \\
\hline Total number of oral hygiene & $\begin{array}{c}8 \\
48 \\
72\end{array}$ & $\begin{array}{c}1.33(2.22) \\
11.87(1.94) \\
12.40(2.17)\end{array}$ & $\begin{array}{l}10.67(2.05) \\
11.93(2.62) \\
12.31(2.19\end{array}$ & $\begin{array}{l}11.00(2.15) \\
11.90(2.29) \\
12.36(2.17)\end{array}$ \\
\hline Total & & $11.84(0.27)$ & $11.64(0.27)$ & \\
\hline Surface of saliva & $\begin{array}{c}8 \\
48 \\
72\end{array}$ & $\begin{array}{l}1.84(0.76) \\
2.11(0.61) \\
2.360 .53)\end{array}$ & $\begin{array}{l}1.60(0.54) \\
2.02(0.40) \\
2.33(0.60)\end{array}$ & $\begin{array}{c}1.73(0.67) \\
2.07(0.52) \\
21.34(0.56)\end{array}$ \\
\hline Total & $2.11(0.07)$ & $1.99(0.07)$ & & \\
\hline Tooth plaque & $\begin{array}{c}8 \\
48 \\
72\end{array}$ & $\begin{array}{l}1.82(0.75) \\
1.87(0.55) \\
2.07(0.39)\end{array}$ & $\begin{array}{l}1.67(0.56) \\
1.93(0.54) \\
0.84(0.56)\end{array}$ & $\begin{array}{l}1.74(0.66) \\
1.90(0.54) \\
1.96(0.50)\end{array}$ \\
\hline Total & & $1.92(0.07)$ & $1.82(0.07)$ & \\
\hline
\end{tabular}

Client-Centered Nursing Care

other words, the two groups (intervention and control) were similar in oral hygiene. Comparison of oral hygiene in terms of variables studied among patients in the intervention and control groups showed that there was no significant difference between them over time (48 and 72 hours) using the duplicate values test (Table 2).

\section{Discussion}

The results showed that there was no significant difference between intervention and control groups in terms of oral hygiene of patients at the beginning of the study (before intervention). In addition, oral hygiene of the patients in the intervention and control groups significantly improved at the end of the study compared to beginning of the study and before intervention. In other words, both mouthwash solutions showed similar effectiveness in improving the oral health of patients hospitalized in ICUs.

The results of this study showed that the oral hygiene of patients hospitalized in ICUs is not desirable during hospitalization. This finding is in line with the results of the study by Monro and Grap who reported that the oral hygiene of patients hospitalized in special care units might already be weak. The results of the current study are also consistent with the report of the Society of Surgeons about oral hygiene in America that revealed oral and dental diseases existed as silent epidemics in the society (Berry 2011).

Comparison of the oral hygiene of patients in the intervention and control groups after the intervention showed that there was no statistically significant difference between the two groups. In other words, the effect of or- 
thodentol and chlorhexidine mouthwashes is the same for oral hygiene. In addition, in a study by DerDioso et al. the prevalence of respiratory infections in patients who used chlorhexidine was less than the placebo group. Given that this substance (chlorhexidine) is not absorbed through the skin and mucous membranes and no dangerous side effects have been reported, it is most commonly used in patients with severe disease. Of course, Monro believes that more studies are needed in this regard (Munro \& Grap 2004). Despite the advice on the use of chlorhexidine, some studies questioned its effectiveness in preventing Ventilator-Associated Pneumonia (VAP). Though the two mouthwashes (orthodentol and chlorhexidine) improved oral hygiene, there was no difference between the two groups after the intervention.

In a study by Ames on 116 patients hospitalized in ICUs, the effects of a regular oral care program (intervention group) and regular care that is run in accordance with the protocol of each section (for control group) were compared against the Beck Oral Examination and the score for oral mucosal plaque. Their results showed that the mean scores in both groups before and after intervention were the same and that regular care, compared to routine care, has significantly improved oral hygiene. In this study, toothbrush was used for intervention group while the use of toothbrushes in the control group is unclear (Safar Abadi \& Ghaznavirad 2012).

Ranjbar et al. conducted a study to investigate the effect of chlorhexidine mouthwash in preventing Superficial VAP and its interaction with the severity of the disease in 80 newly hospitalized patients at Loghman Hospital in Tehran. Their results showed that chlorhexidine mouthwash is more effective on oral hygiene than normal saline (Ranjbar et al. 2010). Nosrat et al. conducted a study in Tehran University of Medical Sciences to examine the impact of effectiveness of Orthodentol mouthwash (carvacrol) on Enterococcus faecalis bacteria as a drug in the canal of the tooth. In their study, it was shown that there is a significant difference between the ability of $6 \%$ carvacrol emulsion and calcium hydroxide in the removal of E. faecalis bacteria after 7-day dressing (Nosrat et al. 2009). In a study by Sageat Al-Islam et al. regarding the effects of antibacterial activity of Khouzestani Savory (carvacrol) on oral pathogens, it was found that Khouzestani Savory with a concentration of $0.31 \mathrm{mg} /$ $\mathrm{ml}$ carvacrol removes oral pathogens (Seghatoleslami et al. 2009). The results of the current study showed that orthodentol solution (which is a herbal compound) and chlorhexidine (which is a chemical medicine) have a similar effect on oral hygiene of patients hospitalized in ICUs. Considering the benefits of herbal compounds, orthodentolcan be used as alternatives to chlorhexidine.

\section{Acknowledgments}

This article is part of the results of the dissertation on nursing conducted as a research project approved by the Shahrekord University of Medical Sciences with project No. 2243 dated 07/10/2016 at the hospitals of Borujen city and Ayatollah Kashani Hospital of Shahrekord. This study has ethical code No. 1395/122 IR.SKUMS.REC, and it is registered with clinical trial No. IRCT number: 2017012232101 NI. Hereby, we express our sincere gratitude towards the executives of the project, members of the research councils of the Faculty of Nursing and Midwifery and Shahrekord University of Medical Sciences, hospital personnel of intensive care units in Shahrekord and Broujen Hospitals, Laboratory of Microbiology in Vali Asr Hospital of Borujen as well as all the patients who participated in the project.

\section{Conflict of Interest}

The authors declare no conflicts of interest.

\section{References}

Adib Hajbaghery, M., Ansari, A. \& Azizi Fini, E., 2011. Oral care in ICU patients: A review of research evidence. KAUMS Journal (FEYZ), 15(3), pp. 280-93

Aronovitch, S. A., 1997. Oral care and its role in WOC nursing Journal of Wound, Ostomy and Continence Nursing, 24(2), pp. 79-85. doi: 10.1097/00152192-199703000-00005

Berry, A. M. et al., 2011. Effects of three approaches to standardized oral hygiene to reduce bacterial colonization and ventilator associated pneumonia in mechanically ventilated patients: A randomised control trial. International Journal of Nursing Studies, 48(6), pp. 681-8. doi: 10.1016/j.ijnurstu.2010.11.004

Berry, A. M. et al., 2011. Effects of three approaches to standardized oral hygiene to reduce bacterial colonization and ventilator associated pneumonia in mechanically ventilated patients: A randomised control trial. International Journal of Nursing Studies, 48(6), pp. 681-8. doi: 10.1016/j.ijnurstu.2010.11.004

Berry, A. M., et al., 2007. Systematic literature review of oral hygiene practices for intensive care patients receiving mechanical ventilation. American Journal of Critical Care, 16(6), pp. 552-62.

Browne, J. A. et al., 2011. Pursuing excellence. Critical Care Nursing Quarterly, 34(1), pp. 25-30. doi: 10.1097/ cnq.0b013e318204809b

Farsam, H. et al., 2004. Composition of the essential oils of wild and cultivatedSatureja khuzistanica Jamzad from Iran. Flavour and Fragrance Journal, 19(4), pp. 308-10. doi: 10.1002/ffj.1300 
Fathi, A., et al., 2011. Application of satureja hortensis L. and Zataria multiflora Boiss: Essential oils as two natural antioxidants in soybean oil during microwave heating. Journal of $\mathrm{Me}-$ dicinal Plants, 3(39), pp. 12-21.

Fourrier, F. et al., 2000. Effects of dental plaque antiseptic decontamination on bacterial colonization and nosocomial infections in critically ill patients. Intensive Care Medicine, 26(9), pp. 1239-47. doi: 10.1007/s001340000585

Grap, M. J., et al., 2003. Oral care interventions in critical care: Frequency and documentation. American Journal of Critical Care, 12(2), pp. 113-8. PMID: 12625169

Hashemi, M.B. et al., 2012. Effect of satureja khuzestanicaessential oil on oxidative stability of sunflower oil during accelerated storage. Natural Product Research, 26(15), pp. 1458-63. doi: 10.1080/14786419.2011.606220

Miranda, A. F. et al., 2015. Oral health promotion in patients with chronic renal failure admitted in the Intensive Care Unit. Clinical Case Reports, 4(1), pp. 26-31. doi: 10.1002/ccr3.437

Munro, C. L. \& Grap, M. J., 2004. Oral health and care in the intensive care unit: State of the science. American Journal of Critical Care, 13(1), pp. 25-34. PMID: 14735645

Munro, C. L. et al., 2009. Chlorhexidine, toothbrushing, and preventing ventilator-associated pneumonia in critically ill adults. American Journal of Critical Care, 18(5), pp. 428-37. doi: 10.4037/ajcc2009792

Nosrat, A., et al., 2009. The effect of Carvacrol on Enterococcus faecalis as a final irrigant. Iranian Endodontic Journal, 4(3), pp. 96-100.

Panchabhai, T. S. et al., 2009. Oropharyngeal cleansing with $0.2 \%$ chlorhexidine for prevention of nosocomial pneumonia in critically ill patients. Chest, 135(5), pp. 1150-6. doi: 10.1378/ chest.08-1321

Pappen, F. G. et al., 2010. Inhibition of sodium hypochlorite antimicrobial activity in the presence of bovine serum albumin. Journal of Endodontics, 36(2), pp. 268-71. doi: 10.1016/j. joen.2009.09.025

Percival, S. L. \& Williams, D. W., 2014. Ventilator-associated pneumonia, endotracheal tubes and biofilms. Biofilms in Infection Prevention and Control, pp. 199-208. doi: 10.1016/b978-012-397043-5.00012-8

Ranjbar, H., et al., 2010. Effect of chlorhexidine gluconate oral rinse on late onset ventilator associated pneumonia prevention and its interaction with severity of the illnes. Iranian Journal Of Critical Care Nursing, 3(2), pp. 81-6.

SafarAbadi, M. \& Ghaznavirad, E., 2012. Comparing the effect of Echinacea and chlorhexidine mouthwash on oral health in patients hospitalized in intensive care units. Complementary Medicine Journal of Faculty of Nursing \& Midwifery, 2(3), pp. 222-34.

Scannapieco, F. A., Wang, B. \& Shiau, H. J., 2001. Oral bacteria and respiratory infection: Effects on respiratory pathogen adhesion and epithelial cell proinflammatory cytokine production. Annals of Periodontology, 6(1), pp. 78-86. doi: 10.1902/ annals.2001.6.1.78

Seghatoleslami, S., et al., 2009. Antibacterial activity of endemic Satureja Khuzistanica Jamzad essential oil against oral pathogens. Iranian Endodontic Journal, 4(1), pp. 5-9. PMCID: PMC3712262
Shafizadeh, F., 2002. [Medicinal plants of Lorestan province (Persian)]. Tehran: Hayyaan Publisher. 